\title{
Shooting the messenger: the science and politics of ethnicity research
}

\author{
Swaran P. Singh
}

\section{Summary}

Scientific arguments showing 'how the world is' are fundamentally different from political assertions about 'how the world should be'. Ideologically motivated political attacks can hamper our understanding of mental disorders by preventing academics from pursuing research in contentious areas. Evidence should be countered by better evidence, not by shooting the messenger.

\section{Declaration of interest}

S.P.S. conducts research on ethnic influences in mental health and runs an early intervention in psychosis service in a multi-ethnic inner-city area.
Swaran P. Singh (pictured) is Professor of Social and Community Psychiatry at the University of Warwick and a consultant psychiatrist with Birmingham Early Intervention Service.

\section{Racism in British psychiatry?}

A petition on the Prime Minister's Office website, dated 23 April 2008, states the following (www.number10.gov.uk/Page15330):

Research shows the discrimination within mental health services has led to marked inequalities in the treatment of care of ethnic minorities with people from African Caribbean communities being routinely subject to the harshest and most punitive treatment. Government research has revealed that Black patients that come in contact with mental health services are more likely to be misdiagnosed, forcibly restrained, over medicated and placed in seclusion despite having similar rates of mental ill health as other ethnic groups. These injustices must be addressed within the law.

In a democracy, such petitions are appropriate mechanisms to demand change or seek redress for perceived institutional failings. Political controversies are harbingers of socioeconomic change and vital in open societies. Scientifically, the assertions made in the petition are factually incorrect. There is clear evidence of high rates of psychotic disorders in Black and minority ethnic groups not attributable to misdiagnosis, ${ }^{1}$ no evidence that ethnicity is an independent predictor of physical restraint, seclusion or 'over medication', or that higher detention rates are due to psychiatric racism. ${ }^{2-4}$ Yet few would argue against the rights of citizens to petition their government.

A more serious problem occurs when ideological positions are used to launch attacks on scientific evidence that contradicts a political assertion or when opinions become 'facts' simply by virtue of repetition. ${ }^{2}$ This editorial argues that a scientific argument, by its very nature, is different from a political assertion. In a conflict between the two, a cautious scientific voice may drown in the political din. Open societies need mechanisms to ensure that scientific research, with its vital dispassionate objectivity, is kept free from political intimidation.

A 2006 BMJ paper on race and mental health argued that ethnic differences in incidence and care pathways in psychosis were not due to institutional racism in psychiatry. ${ }^{5}$ Repeated charges of racism act as a self-fulfilling prophecy by increasing ethnic minority patients' mistrust of services, delaying help-seeking, increasing disengagement and worsening outcomes. The paper met with a chorus of disapproval from race activists and transcultural psychiatry experts, who questioned the credibility, motivation and integrity of the authors. ${ }^{6}$ It received support as well from many eminent clinicians and academics, but the support was private while the disapproval public.

\section{Scientific facts and political assertions}

A scientific argument offers evidence to support a conclusion. A hypothesis is formulated, data carefully collected, findings cautiously interpreted, methodological limitations explicitly acknowledged and new evidence placed in context of previous knowledge. Experts review the new findings with learned scepticism. Scientific research consciously accounts for bias with elaborate mechanisms to filter it out; the success of the scientific method is contingent upon the robustness of these mechanisms. Medical science is also highly cautious about causal attribution. Scientific models aim to explain the world; a faulty model will not stand the rigour of repeat testing and new evidence.

A political assertion is about how the world should be, rather than how it is. Political statements are value-laden, and not simply a dispassionate collection of facts. Politics seeks to change the world in a particular manner and in keeping with specific ideological values. When scientific evidence of ethnic differences in mental disorders is presented as an inequality resulting from discrimination, it clashes with deeply cherished social values of equality and non-discrimination, and provokes a political response. However, health differences between population groups are not necessarily inequalities; illnesses are neither egalitarian in their occurrence nor equitable in their outcomes. Differences per se neither equate with discrimination nor necessarily result from it.

\section{'Medicalised race' and 'racialised medicine'}

Biomedical science has a long and discredited history of racism. From phrenology to eugenics, scientific endeavours have often served racial ideologies. The infamous Tuskegee trials, in which Black patients with syphilis were left untreated even after penicillin had become widely available, has left a lasting legacy of mistrust between Black communities and US health services. ${ }^{7}$ Science cannot claim to be entirely value free. Scientific research mirrors contemporaneous societal values and attitudes. But science has a process of self-correction; new evidence yields greater and better understanding and overturns older views and models, sometimes changing societal attitudes in the process. When a scientific project strays from objectivity, in time it gets discredited. 
Such correction requires challenging the evidence with new or better evidence, not name-calling.

Ethnic differences in disease incidence and outcomes occur in many conditions affecting different systems, for example haemoglobinopathies, inflammatory bowel disease, cardiovascular disease, multiple sclerosis and several types of cancers. Despite substantial concern that biomedical differences between ethnic groups can be misinterpreted as innate genetic differences, ${ }^{8}$ few would argue that race and ethnicity should be completely abandoned as descriptive variables in research. In any attempt to isolate causative factors, all chosen population groups are defined by composite proxy variables that are heavily confounded. Research should endeavour to 'unpack' and isolate the shared biological, cultural and social influence of aetiological importance within and between the ethnic groups under study, rather than ignore ethnic differences.

In 2005, US Food and Drug Administration approval of BiDil (a combination of hydralazine hydrochloride and isosorbide dinitrate) as heart failure treatment specifically for Black patients led to charges that this was 'racialisation of medicine' and 'medicalisation of race. ${ }^{8-10}$ Supporters claimed that reliance on racial classification was an interim path to personalised pharmacotherapy. Critics argued that race was an attractive basis on which pharmaceutical companies could promote their products but once regulatory approval had been obtained, industry had little interest in sponsoring further research that elucidated underlying factors. ${ }^{9}$ Crawley has argued that given the ethnic disparities in cardiovascular morbidity and mortality, 'we cannot wait until all these issues are sorted out. ${ }^{11}$ The best we can do is to be fully informed of the evidence, its limitations and be aware that crude race-based categories could become reified as well-defined biological variables.

Unlike psychiatric debates in the UK, the BiDil arguments have largely been about evidence rather than individuals and the message rather than the messenger. In contrast, the response to the $B M J$ paper was entirely political; no scientific evidence was presented to the contrary. High rates of psychosis in ethnic minority groups were perceived not as an important epidemiological finding that could yield vital aetiological clues, but as personal opinion of academics with illiberal values. Evidence that adverse pathways to care had sociocultural determinants was discounted as an attempt to 'blame the victim'. Statements of facts were turned into statements of values and the message attributed to the messenger.

\section{Protecting scientific integrity}

An objective exploration of race-related differences in mental health is neither to condone nor justify racism. Scientific exactness and objectivity are precisely what we need if we are to understand and eliminate such differences. The assertion that ethnic differences in mental health are due to racism is a prime example of circular reasoning: racism in psychiatry is 'proven' by ethnic differences; ethnic differences 'result' from racism in psychiatry. One reason why academics shirk from challenging such assertions is the fear that rebuttal itself is perceived as evidence of racist prejudice.

User groups are increasingly involved in the commissioning, funding and conduct of research. This is a welcome initiative, providing a much needed corrective to the past neglect of user voice, especially in mental health. We should be mindful though that ideologically committed user bodies can jeopardise research effort that challenges their orthodoxy. Just as we expect researchers to declare financial conflicts of interests, funding bodies and review panels should also be aware of ideological conflicts of interests of panel members. Transparency is in everyone's interest and is essential to ensure quality in research governance.

Organisations such as the Royal College of Psychiatrists have a vital role to play in ensuring that academics feel free and able to pursue research into politically sensitive areas. The College is a professional body, not a political one and should publicly support all ethical research that aims to advance our knowledge and improve our practice. British and European academia has a proud record of conducting high-quality research on social influences in psychosis. Failure to promote such research will have major consequences for scientific advances, service development, patient care and for society at large.

Services cannot develop appropriate interventions to deal with the challenges of our multicultural society unless we are free to openly explore underlying reasons for cultural and ethnic differences. Ethnic minority patients will not get equitable, accessible and appropriate care if resources spent on reducing racism in psychiatry are the wrong solution for an erroneously identified problem. For society as a whole, academic freedom must be a value cherished in itself. Academic freedom ensures that society benefits from best evidence and independent criticism, which politicians are not always able to offer, lest it offends a group or counters a prevailing attitude. Our society needs an honest appraisal of mental health problems that afflict our communities; we can ill afford any restrictions imposed on our scientific endeavours.

Swaran P. Singh, MBBS, MD, FRCPsych, DM, Health Services Research Institute,
Warwick Medical School, University of Warwick, Gibbet Hill Campus, Coventry CV4 7AL, UK. Email: s.p.singh@warwick.ac.uk

First received 31 Aug 2008, final revision 26 Feb 2009, accepted 2 Mar 2009

\section{References}

1 Fearon $\mathrm{P}$, Kirkbride JB, Morgan C, Dazzan $\mathrm{P}$, Morgan $\mathrm{K}$, Lloyd $\mathrm{T}$, et al. Incidence of schizophrenia and other psychoses in ethnic minority groups: results from the MRC AESOP Study. Psychol Med 2006; 36: 1541-50.

2 Singh SP, Greenwood N, White S, Churchill R. Ethnicity and the Mental Health Act 1983. Br J Psychiatry 2007; 191: 99-105.

3 Connolly A, Rogers P, Taylor D. Antipsychotic prescribing quality and ethnicity: a study of hospitalized patients in south east London. J Psychopharmacol 2007; 21: 191-7.

4 Gudjonsson GH, Rabe-Hesketh S, Szmukler G. Management of psychiatric in-patient violence: patient ethnicity and use of medication, restraint and seclusion. Br J Psychiatry 2004; 184: 258-62.

5 Singh SP, Burns T. Race and mental illness: there is more to race than racism. BMJ 2006; 333: 648-51.

6 Mirza M. All in the mind. Catalyst 2007; 2 August (http://83.137.212.42/ siteArchive/catalystmagazine/Default.aspx.LocID-Ohgnew0wu.RefLocID-0hg01b001006009.Lang-EN.htm).

7 Quinn SC, Thomas T, Kumar S. The anthrax vaccine and research: reactions from postal workers and public health professionals. Biosecur Bioterror 2008; 6: $321-33$.

8 Ellison GT, Kaufman JS, Head RF, Martin PA, Kahn JD. Flaws in the U.S. Food and Drug Administration's rationale for supporting the development and approval of BiDil as a treatment for heart failure only in black patients. J Law Med Ethics 2008; 36: 449-57.

9 Bloche MG. Race-based therapeutics. N Engl J Med 2004; 351: 2035-7.

10 Duster T. Medicalisation of race. Lancet 2007; 369: 702-4.

11 Crawley L. The paradox of race in the Bidil debate. J Natl Med Assoc 2007; 99: $821-2$. 